\title{
A Aritmética Escolar (Livro do Mestre) de Roca Dordal no ensino primário em Santa Catarina na primeira metade do século $\mathrm{XX}$
}

\author{
David Antonio da Costa*
}

\section{Resumo}

Este texto tem como objetivo apresentar uma análise do livro Arithmética Escolar: livro do mestre, de Ramon Roca Dordal. Essa obra é um marco do ensino intuitivo da Aritmética em tempos de implantação dos grupos escolares no Brasil. Trata-se de um texto emblemático destinado aos professores do ensino primário para uso em conjunto com a coleção de cadernos de aritmética destinados aos alunos. Fundamentado nas asserções de Darnton (2010), Choppin (2004), Chervel (1990) e Chartier (1990), toma-se o livro didático como fonte de pesquisa privilegiada, revelando aspectos do circuito do livro: desde as prescrições normativas com sua adoção nas escolas públicas assim como alguns aspectos metodológicos acerca do ensino de aritmética. Os resultados apontam a engenhosa articulação efetuada por Roca Dordal, que junto com um grupo de normalistas paulistas construíram as bases para a disseminação de um conjunto de ações que intencionavam a implantação de um ensino moderno, sustentado pela vaga do método intuitivo no ensino primário.

Palavras-chave: Livro Didático. Ensino Primário. Aritmética.

\footnotetext{
* Doutor em Educação Matemática pela Pontifícia Universidade Católica de São Paulo (PUC/SP). Professor do Departamento de Metodologia do Ensino e do Programa de Pós-Graduação em Educação Científica e Tecnológica da Universidade Federal de Santa Catarina (UFSC).
} 


\section{Considerações Iniciais}

O final do século XIX testemunhou muitas mudanças em diversos setores das sociedades ocidentais. No Brasil, particularmente no âmbito da educação, já na República, o estado de São Paulo despontava com um modelo de escola primária fundamentada na implantação dos Grupos Escolares.

Os republicanos planejaram uma escola diferenciada, moderna e com maior qualidade, que levasse à população um conjunto de conhecimentos (também de práticas e valores sociais) que fossem além da alfabetização. Os Grupos Escolares se concretizaram e, com eles, o objetivo de uma formação de qualidade para os professores primários, pois seriam estes os propagadores do ideário republicano que se procurava disseminar. Nóbrega (2003, p. 253) afirma que:

Os grupos escolares podem ser entendidos, de maneira geral, como as primeiras escolas públicas primárias que no Brasil utilizaram-se de uma forma de organização administrativa, programática, metodológica e espacial baseada nas concepções educacionais de tipo "moderno" - já em uso em algumas escolas particulares da época, como a Escola Americana de São Paulo -, fundada num ideal de racionalização, podese dizer numa economia escolar, dominante na Europa e nos EUA na segunda metade do século XIX e início do século XX.

É essa organização em diferentes dimensões apontada pelo pesquisador Nóbrega (2003) que se torna chave para a compreensão dos diversos desdobramentos da implantação desse sistema escolar. Da organização programática, do ponto de vista administrativo, derivou-se uma extensa coletânea de leis, decretos, regulamentos e regimentos. Tudo o que se previa fazer deveria estar documentado e organizado para os diversos agentes da educação: inspetores de ensino, diretores dos grupos escolares, professores normalistas adjuntos etc. Cada um dos protagonistas que atuavam no setor da instrução pública, em tempos da nova república, possuía um papel definido e bem delimitado no organograma institucional das Diretorias de Instrução Pública estaduais, recém-criadas para atender este imbricado modelo administrativo.

E da modernidade que se buscava pelos republicanos, em contraposição às ideias ditas mais conservadoras de um período anterior monárquico, as metodologias fundamentadas no intuitivo ganharam destaque. $\mathrm{O}$ método de ensino intuitivo era proclamado e difundido para uso e implantação nos Grupos Escolares apoiado por materiais didáticos que deveriam responder ao que mais moderno existia na época: cadernos escolares, quadros parentais, mobílias que levassem em conta a ergonomia dos alunos etc. 
Nesse ponto entram em cena os livros didáticos, portadores de conteúdo específico, ideologias, com suas respectivas metodologias de ensino. O importante papel que os mesmos desempenham na condução das implantações dos grupos escolares é destacado de muitas formas. Relativos à sua prescrição e distribuição, o uso dos livros se relaciona aos pareceres oficiais. São documentos que normatizam e oficializam as adoções/aprovações de obras que se alinham com os ideais almejados: teóricos, metodológicos e ideológicos. Há indicações de livros didáticos para uso dos alunos, dos inspetores, para formação de biblioteca escolar e tantos outros. Mas surge também uma nova invenção: o livro didático do professor.

Sendo assim, este artigo trata, de forma especial, do livro de Arithmética Escolar: livro do mestre, de Ramon Roca Dordal (1915). Trata-se de um livro destinado a orientar os professores na condução das práticas pedagógicas, alicerçadas pelo método intuitivo. Essa obra é emblemática e tornase singular pelo processo de sua concepção, elaboração, difusão e uso. Mais do que um manual escrito para professores, este deve ser usado junto com outro grupo de livros - os cadernos de exercícios de Aritmética para os alunos. Concebido para uso nas escolas paulistas, o livro passa a circular também em outros estados.

Santa Catarina foi um dos estados que recebeu apoio do governo paulista na implantação das reformas educacionais, particularmente nos grupos escolares no início do século XX. Um exemplar do Livro do Mestre de Roca Dordal (1915) foi encontrado no Museu da Escola Catarinense, o qual serviu de empiria para a elaboração deste artigo.

O tema em discussão neste texto contribui nos estudos promovidos por um projeto maior denominado "A constituição dos saberes elementares matemáticos: a Aritmética, a Geometria e o Desenho em perspectiva histórico-comparativa, 1890-1970", com apoio do CNPq e coordenado pelo Prof. Dr. Wagner Rodrigues Valente. Esse projeto "guarda-chuva", desenvolvido pela equipe de doutores de dezoito estados brasileiros, tem vistas à elaboração de uma investigação históricocomparativa, cuja temática se relaciona à análise da trajetória de constituição dos saberes elementares matemáticos presentes no curso primário de diferentes regiões do país.

As fontes de pesquisa utilizadas neste artigo, bem como todas as demais que estão sendo mobilizadas para a realização desse projeto maior estão catalogadas e disponibilizadas no Repositório de Conteúdo Digital ${ }^{1}$ da Universidade Federal de Santa Catarina (COSTA, 2015). 


\section{Os livros didáticos tomados como fonte de pesquisa}

As pesquisas que tomam as análises históricas de livros didáticos trazem importantes contribuições para o campo da história das disciplinas escolares (SCHUBRING, 2006; DASSIE; COSTA, 2014). Segundo Chervel (1990. p. 208, grifo nosso):

[...] dos diversos componentes de uma disciplina escolar, o primeiro na ordem cronológica, senão na ordem de importância, é a exposição pelo professor ou pelo manual de um conteúdo de conhecimentos. É esse componente que chama prioritariamente a atenção, pois é ele que a distingue de todas as modalidades não escolares de aprendizagem, as da família ou da sociedade. Para cada uma das disciplinas, o peso específico desse conteúdo explícito constitui uma variável histórica cujo estudo deve ter um papel privilegiado na história das disciplinas escolares.

Tomar os livros didáticos como fontes privilegiadas de pesquisas em história da educação matemática nos permite destacar relações estabelecidas por pelo menos três polos: o texto, o objeto que lhe serve de suporte e a prática que dele se apodera (CHARTIER, 1990). A forma e as disposições gráficas dos enunciados, exercícios, tabelas numéricas, ou seja, toda a estética do seu conteúdo apresenta, grosso modo, uma maior ou menor influência nas apropriações das ideias e dos conteúdos que o livro didático apresenta.

Os livros didáticos, então, assumem diferentes papéis que podem variar consideravelmente dependendo do ambiente sociocultural, da época, das disciplinas, dos níveis de ensino, dos métodos e das formas de sua utilização. Choppin (2004), referência nos estudos relacionados à história do livro didático, diz que:

[...] é preciso levar em conta a multiplicidade dos agentes envolvidos em cada uma das etapas que marca a vida de um livro escolar, desde sua concepção pelo autor até seu descarte pelo professor e, idealmente, sua conservação para as futuras gerações. A concepção de um livro didático inscreve-se em um ambiente pedagógico específico e em um contexto regulador que, juntamente com o desenvolvimento dos sistemas nacionais ou regionais, é, na maioria das vezes, característico das produções escolares (edições estatais, procedimentos de aprovação prévia, liberdade de produção, etc.). Sua elaboração (documentação, escrita, paginação, etc.), realização material (composição, impressão, encadernação, etc.), comercialização e distribuição supõem formas de financiamento vultuosos, quer sejam públicas ou privadas, e o recurso a técnicas e equipes de trabalho cada vez mais especializadas, portanto, cada vez mais numerosas. Por fim, sua adoção nas classes, seu modo de consumo, sua recepção, seu descarte são capazes de mobilizar, nas sociedades democráticas sobretudo, numerosos parceiros (professores, pais, sindicatos, associações, técnicos, bibliotecários, etc.) e de produzir debates e polêmicas. (CHOPPIN, 2004, p. 553-554, grifo nosso). 
A obra de Ramon Roca Dordal (1915), Arithmética Escolar: livro do mestre, torna-se emblemática, pois ela é resultado de uma engenhosa articulação de ordem política e comercial realizada por aqueles que estavam à frente das reformas educacionais em implantação na virada do século XIX para o século XX na escola primária no Brasil republicano. Essa articulação pode ser verificada desde aspectos relativos aos pareceres oficiais para aprovação, uso e adoção de livros didáticos para as escolas públicas, bem como intensa divulgação na imprensa geral propagando um ideário considerado importante para o desenvolvimento da nação republicana.

Na perspectiva de tomar o livro como objeto de estudo, Darnton (2010) propõe um modelo geral para analisar como os livros surgem e se difundem na sociedade. Ainda que isto possa variar de lugar para lugar, de época para época, em linhas gerais é possível identificar que os livros perpassem por um mesmo ciclo de vida, podendo ser descrito como um circuito de comunicação que vai do autor ao editor, ao impressor, ao distribuidor, ao vendedor, e chega ao leitor (Figura 1). A história do livro se interessa por todas essas fases do processo e suas relações com outros sistemas, econômico, social, político e cultural, no meio circundante.

Figura 1 - Invariantes entre fabricação/difusão/consumo dos livros

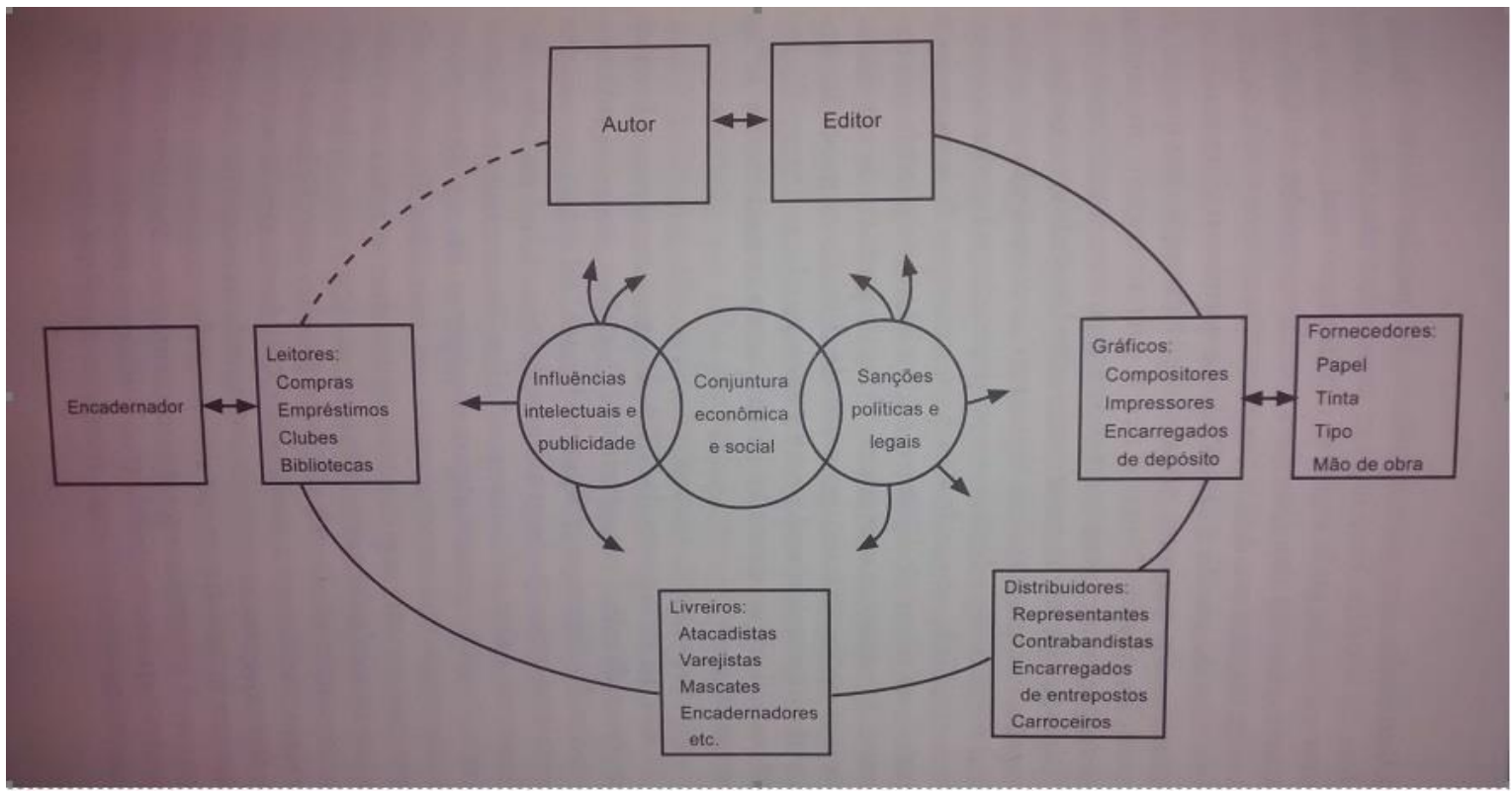

Fonte: Darnton (2010, p. 127).

O modelo de Darnton (2010) indica a trama das possíveis relações entre as diversas fases e os respectivos protagonistas do processo de fabricação de um livro. Permite descrever e analisar a 
materialidade do livro como um produto de atividade humana em seu duplo aspecto: (a) como mercadoria, entendido que passou por um processo de produção onde interveio trabalho humano, sendo então uma cristalização desse esforço humano; e (b) como objeto cultural, onde o livro se apresenta como portador de ideias, de valores culturais.

\section{O conjunto da obra de Roca Dordal: a Aritmética do Mestre e os cadernos de Aritmética para os alunos}

A obra de Roca Dordal (1891a, 1891b, 1891c, 1891d, 1903, 1915) é composta por um conjunto de cadernos de aritmética para uso de alunos e o livro do mestre. Neste artigo evidencia-se o livro Arithmética Escolar: livro do mestre de Roca Dordal (1915), pois é destinado para orientar os professores na marcha das práticas pedagógicas, fundamentadas pelo método intuitivo, em conjunto com os cadernos para os alunos.

Nessa perspectiva, o livro adquire uma função diferenciada de instrução: assume papel de material essencial para o professor na elaboração de suas atividades. A obra deixa de ser um conjunto de lições a serem memorizadas pelos alunos e passa a servir de apoio nas atividades docentes. Essa característica, livro para uso docente ou manual didático, não é uma inovação de Roca Dordal, mas era uma tendência pouco difundida na época e que começou a se proliferar, segundo Valdemarin (1998), frente a tantas proposições inovadoras advindas das novas metodologias de ensino.

Os cadernos de Aritmética de Ramon Roca Dordal são compostos por seis volumes para uso no ensino primário. Foram publicados pela editora Teixeira \& Irmão e posteriormente pela Miguel Melillo e Cia. O texto da tese de Costa (2010) indica que foram localizados os quatro primeiros cadernos ${ }^{2}$ (I, II, III e IV - respectivamente) dessa coleção no acervo da biblioteca da Faculdade de Educação da Universidade de São Paulo (FE-USP) (ROCA DORDAL, 1891a, 1891b, 1891c, 1891d). Esses exemplares são da primeira edição, datada em 1891. Há também menção sobre uma quarta edição do quarto caderno $^{3}$ (IV) do ano de 1903 (ROCA DORDAL, 1903). Tratava-se dos primeiros cadernos de exercícios de aritmética criados e desenvolvidos para serem utilizados pelos alunos das escolas públicas, isto é, dos grupos escolares.

Em todos os cadernos encontramos uma mensagem com quatro parágrafos de Roca Dordal (1891a) dirigida aos professores: 
A pratica mostra que o ensino da arithmetica ha de ser dado quase individualmente, pois raras vezes dous ou mais alumnos caminham parallelamente no estudo desta disciplina.

Publicando a Artihmetica Escolar creio facilitar nas escolas o ensino da sciencia dos numeros, dando aos Professores um meio para que depois das explicacoes necessarias a cada classe, ate comprehensao da regra exposta na respectiva licao, possam verificar o trabalho dos alumnos, avaliando o aproveitamento, fornecendo novas explicacoes e novos exercicios aos que nao tiverem comprehendido, e guiando os outros a proseguir.

Em nossas escolas, entregues aos cuidados de um so professor, obrigado a leccionar grande numero de discipulos, uma das dificuldades para o rapido e facil conhecimento da arithmetica consiste na falta de cadernos, em que se apresente ao alumno uma serie de problemas e exercicios dispostos graduamente e como applicacao da teoria ministrada methodicamente.

Por isso, acceitando um offerecimento dos conhecidos editores Teixeira \& Irmao, que tanto servicos tem prestado dando livros uteis ao ensino, apresento a primeira edicao desta primeira serie da Arithmetica Escolar, que dedico a Infancia, esperando dos mestres a necessaria critica para melhorar este ensaio de um genero completamente novo para nos.

Itatiba 1891. (ROCA DORDAL, 1891a, p. i).

$\mathrm{Na}$ mensagem o autor apresenta a metodologia do ensino e a forma de uso dos cadernos. Para Roca Dordal (1891a), estes poderiam ser utilizados como um meio de verificação dos trabalhos dos alunos após a explicação dada pelo professor, permitindo ainda que o professor completasse com novos exercícios aqueles que não tivessem obtido aproveitamento satisfatório. A inovação proposta nesses cadernos trazia a modernidade do acompanhamento dos alunos de forma "quase" individual, sem deixar de tratar a classe em seu coletivo, atingindo as normas de racionalidade prescritas pelo ideário educacional vigente, isto é, ensino simultâneo obtido pela simultaneidade do método empregado pelo uso do material didático.

Além disso, Roca Dordal destaca o uso dos cadernos como uma solução aos professores que ministram aulas a grande número de discípulos, onde certamente o professor encontraria alunos com diferentes níveis de conhecimentos sobre os conteúdos que estariam sendo ministrados.

Infere-se que o Livro do Mestre ${ }^{4}$ (ROCA DORDAL, 1915) somente surge em período posterior aos lançamentos dos cadernos de aritmética para alunos. Conforme as próprias palavras de Ramon Roca Dordal (1903): em suas considerações do quarto caderno de aritmética:

Com esta Quarta Edição, atentamente revista, apparece tambem um nitido volume contendo os exercicios e problemas dos seis cadernos da Arithmetica Escolar, todos resolvidos.

Este LIVRO DO MESTRE, agora publicado, vem facilitar ainda mais a tarefa dos senhores Professores. 
Agradece assim o acolhimento dispensado a seu despretensioso trabalho, o autor. (ROCA DORDAL, 1903, grifo nosso).

O guia pedagógico, Livro do Mestre, foi organizado visando contemplar as lições dos seis cadernos de Aritmética. Roca Dordal (1915) adverte nesse livro que cada página da obra contém duas dos respectivos cadernos, isto é, a lição e seus problemas correspondentes. A indicação da página e cadernos a que a lição pertence é especificada no canto superior direito da folha, o que torna fácil a localização das páginas equivalentes.

O Livro do Mestre é composto por 180 lições, divididos em seis grupos de trinta lições. Cada um desses grupos se associam a um caderno dos alunos. A distribuição dos conteúdos apresenta uma organização gradual de dificuldade e à medida que o aluno avança nas lições o nível de aprofundamento é maior. Os assuntos sobre numeração, soma, subtração, multiplicação, divisão, números romanos, decimais, sistema métrico, frações, divisibilidade e moeda brasileira são distribuídos e intercalados ao longo dos seis livros (ROCA DORDAL, 1915).

Infere-se que as concepções do método intuitivo influenciaram a disposição dos conteúdos por cadernos. Destacam-se alguns elementos que caracterizam tal método: a abordagem dos assuntos é realizada indutivamente; iniciam-se os estudos com apoio de exemplos; as quatro operações elementares são abordadas gradativamente, aumentando sua dificuldade com o decorrer das lições; o sistema métrico ganha destaque principalmente pela sua relação com a prática. Alguns conteúdos são exemplificados com notas de compras e venda para abordagem da moeda brasileira.

Ainda que as rubricas das operações sejam destacadas de forma sequencial no livro, não significa que elas não sejam abordadas em conjunto. Por exemplo, para dar conta da marcha do ensino intuitivo, o livro explora a possibilidade do estudo analítico do número. Dito de outra forma, por exemplo, nos primeiros problemas de numeração já se apresentam elementos de soma, subtração, multiplicação e divisão. É o caso das questões denominadas "Problemas" na página 2 do Livro do Mestre, associadas às páginas 3 e 4 do caderno I:

1. Reunindo 2 livros, e 3 livros, e 1 livro, e 4 livros, quantos terá?

2. Juntando um, e um, e dois, e um, e tres, quanto será ao todo, e quanto metade?

3. Quantos grupos de dous se contém no numero oito, e quantos de tres no numero nove?

4. Tres e cinco, quantos são?

5. 2 mais 1 , mais 4 , quanto é?

6. De oito tirando cinco, quanto fica?

OBSERVAÇÃO: Esta lição e as seguintes são organizadas para que os alumnos se exercitem na representação graphica dos algarismos, e bem assim no calculo mental, 
base necessaria para o desenvolvimento da intelligencia infantil. (ROCA DORDAL, 1915, p. 2).

\section{O circuito do livro na obra de Roca Dordal}

A obra de Roca Dordal apresenta diversos desses elementos em destaque. No primeiro momento trago o perfil do autor. Para Costa (2010), a centralização e hegemonia do ensino primário paulista, a partir da Escola Normal Caetano de Campos, evidenciou um grupo de normalistas que lá se formaram e que, além de exercerem cargos-chave na hierarquia da Instrução Pública, muitos deles se tornaram autores de livros didáticos.

O autor Ramon Roca Dordal é exemplo emblemático. Em 1886, com 32 anos, matriculou-se na Escola Normal de São Paulo; diplomado em 1889, foi nomeado para a $1^{\text {a }}$ Cadeira de Itatiba, SP. Lecionou na $1^{\text {a }}$ Escola Modelo na cidade de São Paulo, também chamada "Escola Modelo do Carmo", e, em fevereiro de 1893, foi auxiliar de Alfredo Bresser, tendo permanecido nessa escola por 10 anos. Foi colaborador da revista A Eschola Publica que circulou na cidade de São Paulo e compôs, em 1902, o grupo de redatores oficiais da Revista de Ensino nessa mesma cidade. Com expressiva participação no magistério público paulista e transitado por diferentes cargos e funções relativos à instrução pública, em 1907, Roca Dordal foi nomeado inspetor escolar na cidade de São Paulo até o ano de 1919, quando se aposentou (COSTA, 2010).

A biografia de Roca Dordal permite inferir sua efetiva participação desse grupo hegemônico dos normalistas paulistas aos quais estavam destinados a condução da implantação das reformas, já explicitadas anteriormente. Resta avaliar as motivações prescritivas, isto é: quais foram os mecanismos mobilizados para assegurar a esta obra o seu devido lugar?

Em tempos de reformas educacionais, final do século XIX, início do século XX, os diversos grupos escolares implantados no estado de São Paulo e, posteriormente nos demais estados da federação, potencializou o mercado dos livros didáticos. Essa ação não se torna isolada e sim imbricada com o mercado editorial, pois se havia escola, deveria haver também uma prescrição sobre quais obras didáticas deveriam ser recomendadas e/ou adotadas.

Esse processo é explicado mediante o entendimento das ações de controle que são exercidas no chamado circuito do livro escolar. Em São Paulo, desde o início da República, o governo controla a adoção dos livros didáticos nas escolas por meio da emissão de Pareceres Oficiais de Obras Didáticas. 
Na prática, sob a alegação da necessidade de uniformização do ensino respondendo a organização administrativa pedagógica, ou ainda por legislar sobre programas e currículos, o estado torna-se o principal comprador desse produto. Isso significa que um provável sucesso editorial comece com as indicações positivas nos pareceres oficiais.

O artigo de Costa (2014) analisa as adoções de obras didáticas de aritmética em São Paulo e em Santa Catarina, onde constam nos dois estados os respectivos pareceres favoráveis a indicação da obra de Dordal, isto é, a Arithmetica Escolar: livro do mestre, bem como a coleção de cadernos Arithmetica Escolar.

O parecer das obras didáticas de acordo com o Decreto $n^{0} 596$, de 7 de junho de $1911^{5}$ (SANTA CATARINA, 1911), em Santa Catarina, fundamentado no modelo de São Paulo, mostra a amplitude da ação desse grupo de normalistas paulistas sobre as obras didáticas numa dimensão que ultrapassa as fronteiras do próprio estado.

Nas páginas iniciais da obra, a seção denominada de "Algumas palavras de distinctos colegas", como Oscar Thompson, Rui Puiggari, Arnaldo de Oliveira Barreto, René Barreto, Luiz Galvão de Moura Lacerda, Pedro Voss e Tancredo do Amaral - a elite dos normalistas paulistas -, apresentam-se as transcrições de notas de apoio em periódicos, que expressam e enaltecem muitos elogios sobre a obra.

[...]. Ele seguiu um methodo pratico, o mais simples possivel e nisso fez muito bem, pois mostrou comprehender que, para ensinar as crianças, é preciso descer, nivelar as forças de nossa intelligencia com as da intelligencia da criança; pôr tudo no mesmo plano para facilitar a passagem a acceitação dos conhecimentos que se tem de transmitir. Do Diario Popular de 10 de Março de 1892.

Nós que conhecemos a difficuldade no ensino de tal disciplina a crianças, cujo espirito naturalmente ainda não está afeito a abstracções, e para cujo ensino adoptavam-se compendios mais theoricos que práticos, portanto fóra da sua comprehensão, encontramos no methodo de que tratamos muitas vantagens sobre todos os outros que ainda lêmos. Do Correio de Campinas, 25 de Outubro de 1893.

[...] A estes [alunos] fornece o modo concreto, rapido e efficaz de aprender a sciencia dos numeros, e aquelles um methodo aperfeiçoado e seguro, de facilima applicação individual, seja qual fôr o grão de intelligencia do alumno.

Conhecendo o erro, aliás commum em nossas escolas, de ensinar-se arithmetica por um processo expositivo e abstracto, sofrendo a cerebração infantil consideraveis damnos, o illustre auctor da Arithmetica Escolar, fundado na observação e na pratica, estabelece o modo de sanar este mal. Da Gazeta de Jacarehy de 24 de abril de 1892. (ROCA DORDAL, 1915, p. ii, grifo nosso).

Outro ponto que merece destaque trata-se da editora associada a essa obra. Nesse caso, a Livraria Francisco Alves \& Cia, tradicional casa editorial fundada em 1854, presente inicialmente no 
Rio de Janeiro. Rapidamente ela se ajusta aos impulsos do mercado que se abria com as implantações dos grupos escolares e escolas normais e expandem seus negócios em São Paulo, que abriu sua primeira agência paulista em 1894, conquistando um significativo salto qualitativo em seus lançamentos, particularmente no segmento de ensino elementar. Ter os normalistas no rol de autores de livros de seu catálogo também em muito influencia a distribuição das obras nas demais localidades (COSTA, 2010).

No texto em análise, datado de 1915, há três endereços comerciais da Livraria Francisco Alves \& Cia impressos na capa do livro, o que destaca sua presença nos grandes centros comerciais desse período em destaque: Rua do Ouvidor, 166, Rio de Janeiro; Rua de São Bento, 65, São Paulo; e Rua da Bahia, Belo Horizonte.

\section{As notas explicativas da Arithmetica Escolar: livro do mestre}

O livro em análise possui estampado logo na sua capa o título e subtítulo: A Arithmetica Escolar: Livro do Mestre - Guia Pedagógico: Solução dos dous mil exercicios e mil problemas contidos nos seis cadernos de Roca Dodal (1915).

É interessante observar pelas notas de orientação/observação presentes ao longo do livro a marcha que o autor impõe na condução de sua obra, revelando sua metodologia. Relacionado à primeira lição, cujo tema é "Numeração", há três problemas com enunciados que apontam a interlocução do professor com alunos mediante as palavras que expressam os números e seus respectivos sinais, termo utilizado por Roca Dordal para designar algarismos. E como os problemas tratam das palavras e sinais, não se apresentam resultados, apontando ao professor que tais respostas podem ser "dadas á primeira vista" (ROCA DORDAL, 1915, p. 1). De fato, implícito a essas orientações destacadas na primeira nota de orientação ao professor estão as ideias acerca das concepções do ensino de aritmética de Roca Dordal.

O pesquisador Oliveira (2015) apresenta importantes considerações acerca do método de intuitivo de Pestalozzi sobre o ensino de aritmética. Para o autor, com o propósito de exercitar e testificar a aquisição da ideia de número, o pedagogista suíço aconselha o professor a pegar um objeto e perguntar a criança: tenho nas mãos muitos objetos? Se a criança de fato estivesse familiarizada com tal ideia responderia: não, tem apenas $u m$. Em seguida levantaria dois objetos e tornaria a pergunta. A 
resposta dada pela criança é que garante a marcha do aprendizado e do avanço dos estudos. Dito de outra forma, as atividades orais e o cálculo mental são ações valorizadas na metodologia pestalozziana, fundamento do método intuitivo.

Seguem algumas outras observações e notas que exprimem a marcha do método empregado por Roca Dordal em sua obra, consoante ao método intuitivo de Pestalozzi.

Observação - Esta lição e as seguintes são organizadas para que os alumnos se exercitem na representação graphica dos algarismos, e bem assim no calculo mental, base necessaria para o desenvolvimento da intelligencia infantil. [p. 3 e $4-1^{\circ}$. Caderno] - Lição II - Numeração

Nota - As soluções não estão todas apresentadas, attenta a facilidade das respostas, ainda mais desnecessarias ao considerar que estes primeiros exercicios devem ser principalmente oraes, como meio de verificação do preparo intellectual do alumno, e ensaio para estudo que elle emprehende. [p. 5 e 6 - $1^{\circ}$. Caderno] - Lição III - Sommar. Observação - Nesta lição e nas que tratam de numeração o professor deve verificar si o alumno escreve e lê com facilidade os pequenos numeros que lhe forem dictados. [p. 45 e $46-1^{\circ}$. Caderno] - Lição XXIII - Numeração. (ROCA DORDAL, 1915, p. 2-3).

E mesmo avançando no conteúdo, quando se aborda o ensino de fração, a partir do quinto caderno, ainda assim há observações para que o professor de classe fique atento aos aspectos relacionados ao cálculo mental e siga o guia do mestre dando ênfase à:

Observação - Ao encetar o estudo das fracções, convém que os alumnos resolvam mentalmente muitas operações pequenas, com o fim de se habituarem a raciocinar a respeito das fracções, do mesmo modo que nos inteiros. [p. 21 e $22-5^{\circ}$. Caderno] Lição XI - Fracções. (ROCA DORDAL, 1915, p. 131).

Vale destacar que as lições sobre o ensino de fração são posteriores às lições dos números decimais. Isto é, para Roca Dordal o ensino dos decimais deve anteceder ao ensino das frações. De fato, após explorar as somas, subtrações e multiplicações com decimais no terceiro caderno, o autor inicia a lição um do quarto caderno de aritmética com a divisão dos decimais (ROCA DODAL, 1891d). Na lição cinco deste mesmo caderno se inicia o conteúdo de sistema métrico. Notadamente, para Roca Dordal (1891d) deveria haver a prevalência do estudo dos números decimais antecedendo os estudos das frações ordinárias. A abordagem desse último conteúdo somente entra em cena a partir da lição XI do quinto caderno, posteriormente, ainda, à lição da "Moeda Brasileira" (ROCA DORDAL, 1903).

$\mathrm{O}$ autor ainda dedica a última nota impressa em sua obra, reforçando sua ideia acerca do ensino da fração: 
Observação - Ao resolver os problemas em que entram fracções ordinarias, podem estas ser transformadas em decimaes, o que muito facilita a solução dos problemas, simplificando as operações a effectuar. [p. 49 e $50-6^{\circ}$. Caderno] - Lição XXV Reducção de fracções ordinarias a decimaes. (ROCA DORDAL, 1915, p. 175).

\section{Considerações Finais}

Tomar a obra de Roca Dordal nos permite dialogar, a luz dos referenciais de Darnton (2010) e Choppin (2004), e compreender a engenhosa articulação do circuito do livro com seus respectivos e diversos papéis empreendidos por este autor, os textos normativos, a casa editorial e o estado - cliente final - no contexto da implantação de uma nova organização escolar que privilegiava e propagava o método intuitivo no curso primário no Brasil republicano.

Roca Dordal, autor inserido no grupo de normalistas paulistas imbuídos na tarefa da propagação de um novo ideário de ensino, exerce posições-chave na hierarquia da Instrução Pública. Sua posição legitima-o como autor de livro didático. Essa situação aproxima-o da Livraria Francisco Alves, casa editorial que demostra uma grande agilidade comercial e expande-se rapidamente em direção aos principais centros urbanos na virada do século XIX para o século XX no Brasil.

Com as chancelas dos pareceres oficiais, isto é, com as recomendações e adoções por parte do estado de sua obra, Ramon Roca Dordal idealiza um conjunto de seis cadernos de aritmética para uso dedicado aos alunos. Tangenciando ao anacronismo, trata-se de um primeiro livro consumível para alunos, uma vez que previa espaço para preenchimento e cálculo no seu interior, concebido no Brasil.

Delineado por um conjunto de lições devidamente cadenciadas e fundamentadas no método intuitivo para o ensino de aritmética, o autor inova mais uma vez quando lança o guia para o mestre, ou seja, um volume específico contendo as soluções e respostas para os dois mil exercícios e mil problemas propostos no conjunto dos seis cadernos. Em termos práticos, mais uma inovação, pois se trata do lançamento do primeiro livro do mestre do mercado editorial brasileiro.

Encontrar um exemplar do livro do mestre de Ramon Roca Dordal no Museu da Escola Catarinense nos dá pistas da materialização da circulação desse livro em Santa Catarina. Ou seja, há exemplar físico que remonta os tempos da vigência das normativas relativas a adoção dos livros didáticos nas escolas por meio da emissão de Pareceres Oficiais de Obras Didáticas deste estado.

Estudar os conteúdos desse livro, bem como confrontá-lo com os programas, segundo Chervel (1990), permite-nos compreender aspectos da história da disciplina escolar, no presente caso, da 
aritmética do ensino primário. Dessa forma, tais estudos potencializam os pesquisadores da história da educação matemática ampliarem o conhecimento acerca dos modelos pedagógicos que circularam nesse período no Brasil.

\section{Notas}

${ }^{1}$ Ver em: <https://repositorio.ufsc.br/handle/123456789/1769>. Acesso em: 30 abr. 2015.

${ }^{2}$ Uma cópia digital dos cadernos I, II, III e IV está disponível no Repositório Institucional da Universidade Federal de Santa Catarina (UFSC) e podem ser acessados, respectivamente: $<$ https://repositorio.ufsc.br/handle/123456789/1774>; $<$ https://repositorio.ufsc.br/handle/123456789/1785>; $<$ https://repositorio.ufsc.br/handle/123456789/1786>; <https://repositorio.ufsc.br/handle/123456789/1787>. Acesso em: 30 abr. 2015.

${ }^{3}$ Ver também em: <https://repositorio.ufsc.br/handle/123456789/1808>. Acesso em: 30 abr. 2015.

${ }^{4}$ Uma cópia digital desse livro datado de 1915, encontra-se disponível no Repositório Institucional da UFSC. Disponível em: <https://repositorio.ufsc.br/handle/123456789/126787>. Acesso em 30 abr. 2015.

${ }^{5}$ Disponível em: < https://repositorio.ufsc.br/handle/123456789/123490>. Acesso em 30 abr. 2015.

\section{REFERÊNCIAS}

CHARTIER, Roger. Textos, impressos, leitura. In: CHARTIER, Roger. A História Cultural: entre práticas e representações. Tradução de M. Gallardo. Rio de Janeiro: DIFEL; Bertrand Brasil, 1990. p. 121-139.

CHERVEL, André. História das disciplinas escolares: reflexões sobre um campo de pesquisa. Teoria \& Educação, Porto Alegre, v. 2, p. 177-229, 1990.

CHOPPIN, Alain. História dos livros didáticos e das edições didática: sobre o estado da arte. Educação e Pesquisa, São Paulo, v. 30, n. 3, p. 549-566, set./dez. 2004.

COSTA, David Antonio da. A aritmética escolar no ensino primário brasileiro: 1890-1946. 2010. 278f. Tese (Doutorado em Educação Matemática) - Pontifícia Universidade Católica de São Paulo, São Paulo. 2010.

COSTA, David Antonio da. Um exemplo de estudo histórico comparativo sobre a adoção de livros didáticos de aritmética em São Paulo e em Santa Catarina no ensino primário: 1890 - 1930. Revista da Rede Amazônica de Educação em Ciências e Matemática, Cuiabá, MT, v. 1, p. 47-59, 2014.

COSTA, David Antonio da. Repositório. In: VALENTE, Wagner Rodrigues (Org.). Cadernos de Trabalho. São Paulo: Editora Livraria da Física, 2015. v. 3.

DARNTON, Robert. O beijo de Lamourette: mídia, cultura e revolução. Tradução de Denise Bottmann. São Paulo: Companhia das Letras, 2010. 
DASSIE, Bruno Alves; COSTA, David Antonio da. Livros didáticos como fonte: o que dizem as pesquisas brasileiras do I ENAPHEM. In: VALENTE, Wagner Rodrigues (Org.). História da Educação Matemática no Brasil: problemáticas de pesquisa, fontes, referências teórico-metodológicas e histórias elaboradas. São Paulo: Editora Livraria da Física, 2014. v. 1. p. 200-209.

NÓBREGA, Paulo de. Grupos escolares: modernização do ensino e poder oligárquico. In: DALLABRIDA, Norberto. Mosaico de escolas: modos de educação em Santa Catarina na primeira república. Florianópolis: Cidade Futura, 2003. p. 253-280.

OLIVEIRA, Marcus Aldenisson de. Método. In: VALENTE, Wagner Rodrigues (Org.). Cadernos de Trabalho. São Paulo: Editora Livraria da Física, 2015. v. 4.

ROCA DORDAL, Ramon. Arithmetica escolar: exercicios e problemas para as escolas primarias, familias e collegios. Primeiro caderno. São Paulo: Teixeira \& Irmãos, 1891a. Disponível em: $<$ https://repositorio.ufsc.br/handle/123456789/1774>. Acesso em: 30 abr. 2015.

ROCA DORDAL, Ramon. Arithmetica escolar: exercicios e problemas para as escólas primarias, familias e collegios. Segundo caderno. São Paulo: Teixeira \& Irmãos, 1891b. Disponível em: <https://repositorio.ufsc.br/handle/123456789/1785>. Acesso em: 30 abr. 2015.

ROCA DORDAL, Ramon. Arithmetica escolar: exercicios e problemas para as escólas primarias, familias e collegios. Terceiro caderno. São Paulo: Teixeira \& Irmãos, 1891c. Disponível em: <https://repositorio.ufsc.br/handle/123456789/1786>. Acesso em: 30 abr. 2015.

ROCA DORDAL, Ramon. Arithmetica escolar: exercicios e problemas para as escólas primarias, familias e collegios. Quarto caderno. São Paulo: Teixeira \& Irmãos, 1891d. Disponível em: <https://repositorio.ufsc.br/handle/123456789/1787>. Acesso em: 30 abr. 2015.

ROCA DORDAL, Ramon. Arithmetica escolar: exercicios e problemas para as escólas primarias, familias e collegios. Quarto caderno. 4. ed. São Paulo: Miguel Melillo \& Cia, 1903. Disponível em: <https://repositorio.ufsc.br/handle/123456789/1808>. Acesso em 30 abr. 2015.

ROCA DORDAL, Ramon. Arithmetica Escolar: livro do mestre. São Paulo: Livraria Francisco Alves, 1915. Disponível em: <https://repositorio.ufsc.br/handle/123456789/126787>. Acesso em 30 abr. 2015.

SANTA CATARINA. Decreto n. 596, 7 julho 1911. Adoptando para serem exclusivamente usadas em todas as Escolas publicas estaduaes as obras didacticas. Acervo APESC, Florianópolis, 1911. Disponível em: <https://repositorio.ufsc.br/handle/123456789/123490>. Acesso em: 30 abr. 2015.

SCHUBRING, Gert. Researching into the History of Teaching and Learning Mathematics: the State of the Art. Paedagogica Historia, v. 42, n. 4-5, p. 665-678, ago. 2006. 
VALDEMARIN, Vera Tereza. Método intuitivo: os sentidos como janelas e portas que se abrem para um mundo interpretado. In: SOUZA, Rosa Fátima de; VALDEMARIN, Vera Tereza: ALMEIDA, Jane Soares (Org.). O legado educacional do século XIX. Araraquara, SP: UNESP - Faculdade de Ciências e Letras, 1998. p. 63-100. 


\section{Roca Dordal's Arithmetic School education in Santa Catarina in the first half of the twentieth century}

\begin{abstract}
This text aims to present a book review of Ramon Roca Dordal's Arithmetic School (Teacher's Book). This work is a landmark of intuitive arithmetic teaching in times of implementation of school groups in Brazil. It is an emblematic text intended for primary school teachers to use in conjunction with the collection of arithmetic books which were used by the students. Based on Darnton (2010), Choppin (2004), Chervel (1990) and Chartiers assertions (1990), this text takes up the textbook as a privileged source research and it reveals some aspects of the book circuit: from the prescriptive requirements with its adoption in public schools as well as some methodological aspects about numeracy. The results show the ingenious articulation made by the author who along with a teaching students group from São Paulo built the foundation for the spread of a set of actions that were aimed at the establishment of a modern teaching, supported by a wave of intuitive method in primary education.
\end{abstract}

Keywords: Textbook. Elementary school. Arithmetic.

David Antonio da Costa

E-mail: david.costa@ufsc.br
L'arithmétique scolaire (Le Livre de L'enseignant) de Roca Dordal dans l'enseignement primaire à Santa Catarina dans la première moitié du XXe siècle

\section{Résumé}

Ce texte vise présenter une analyse du livre L'arithmétique scolaire: le livre de l'enseignant, de Ramon Roca Dordal. Ce travail est un point de repère de l'enseignement intuitive de l'arithmétique dans les temps de la mise en œuvre de groupes scolaires au Brésil. Il est un texte emblématique destiné aux enseignants des écoles primaires pour être utilisé en conjonction avec la collection de livres arithmétiques destinés aux étudiants. Basé sur les affirmations de Darnton (2010), Choppin (2004), Chervel (1990) et Chartier (1990), on prends le manuel comme une source privilégiée de recherche, en révélant des aspects du circuit du livre: des les prescriptions normatives adoptées par les écoles publiques ainsi que certains aspects méthodologiques sur la numératie. Les résultats montrent l'articulation ingénieuse faite par Dordal avec un groupe de normaliens de São Paulo qui ont construit les bases pour la diffusion d'un ensemble d'actions avec l'intention de mise en œuvre un enseignement moderne, soutenue par une vague de méthode intuitive dans l'enseignement primaire.

Mots-clés: Manuels Scolaires. École Primaire. Arithmétique.

Enviado em: 20/5/2015

Aprovado em: 14/11/2015 